\title{
Küresel Kamu Özel Ortaklığı Uygulamaları ve Türkiye Sağlık Sektörü Açısından Bir Değerlendirme
}

\author{
Perihan ŞENEL TEKIN ${ }^{1}$ \\ ${ }^{\text {I} A n k a r a ~ U ̈ n i v e r s i t e s i ~ S a g ̆ l ı k ~ H i z m e t l e r i ~ M e s l e k ~ Y u ̈ k s e k o k u l u, ~ A n k a r a . ~}$ \\ E-mail:ptekin@ankara.edu.tr
}

\begin{abstract}
Özet
Son kırk yılda neo-liberalizmin etkisi altında kalan ülkelerin kamu mal ve hizmet sunumunda finansman ihtiyacını karşılamada ciddi değişimler yaşanmıştır. Kamu bütçeleri ile karşılanması mümkün olmayan büyük ölçekli yatırımlar için farklı alternatif finansman yöntemlerini araştıran ülkeler için, kamu-özel sektör ortaklığı (KÖO) yöntemi, çeşitli ölçeklerde yatırımları kısa sürede gerçekleştirebilme firsatı yaratmışıtır. Ulaşım, enerji, eğitim, sağlık, savunma ve çeşitli altyapı yatırımları gibi birçok sektörde kullanılan KÖO, ilk olarak İngiltere ve Amerika Birleşik Devletleri gibi ülkelerce kullanılan alternatif bir finansman yöntemi olmuştur. Bu yazının amacı, genelde KÖO yöntemini kullanarak kamu hizmet finansmanını sağlayan ülke deneyimlerine bir bakış; özelde ise, Türkiye sağlık sektör uygulamalarına iliş̧in genel bir değerlendirme sunmaktır.
\end{abstract}

Anahtar Kelimeler: Kamu özel ortaklığı, Köo, Sağlık hizmetleri, Ülkeler, Sağlık, Türkiye

\begin{abstract}
In the last four decades, countries under the influence of neo-liberalism have undergone serious changes in meeting the need for financing public goods and services. The publicprivate partnership (P3) method has created an opportunity for short-term investments in various scales for countries that are exploring different alternative financing methods for large-scale investments that can not be met with public budgets. P3, used in many sectors such as transportation, energy, education, health, defense and various infrastructural investments, has been an alternative method of financing, first using the countries such as the United Kingdom and the United States. The purpose of this paper is to give an overview of the country experiences that provide public service financing, usually using the P3 method; in particular, to provide a general assessment of health sector practices in Turkey.
\end{abstract}

Keywords: public private partnership, p3, health services, countries, health, turkey 


\section{Kamu Özel Ortaklığı}

Seksenli yıllardan itibaren değişen dünya düzeni ile beraber devletlerin vatandaşlarına sağladığı kamu mal ve hizmet sunumunda da ciddi değişimler yaşanmaktadır. Gerek idareler üzerindeki finansal baskılar gerekse kamu yönetim ve iş yapma anlayışının günün ihtiyaçlarına cevap verememesinden kaynaklansın, bir çok ülke kamunun hakim olduğu sektörlerde özel sektörle ortaklıklar kurma yoluna gitmektedir. Son 40 yılda İngiltere'den diğer ülkelere yayılan Kamu-Özel Ortaklığı (KÖO) yöntemi 90'lı yıllardan itibaren enerji ve ulaştırma sektörleri ile Türkiye'de de kullanılmaya başlanmıştır.

Devletlerin temel görevlerinden olan kamu hizmet alanı son kırk yılda tüm dünyada hızlı bir değişim yaşamaktadır. Özellikle kamu hizmetlerine olan talebin hızla artmasına karşın kamu finansman kaynaklarının yetersizliği ile finansman sıkıntısı çeken hükümetler bu konuda yeni politikalar üretmeye başlamıştır (Goldman ve Mokuvos, 1991, s.25-28; Broadbent ve Laughlin, 2003; Broadbent ve Laughlin, Şubat 2005; Hemming, 2006, s.1).

Seksenli yıllarda İngiltere'den tüm dünyaya yayılan kamu hizmet sunumuna yönelik değişiklikler kısa sürede tüm dünyayı etkisi altına almıştır (UN, s.1993, 13; Morledge ve diğerleri, 2006, s.196-197; Yescombe, 2007; Holden, 2009, s.313-332). Bu değişimle birlikte devletler iktisadi alanda sürdürmekte oldukları işletmecilik faaliyetlerini özel sektöre devretmeye başlamışlardır. 'Birinci Özelleştirme Dalgası' olarak nitelendirilebilecek bu uygulama ile devlet üretici/işletmeci kuruluşlarını satış vb yollarla tümüyle özel sektöre devrederek özel hukuk kurallarına bağlı olarak rekabetçi ortamda çalışmalarını sağlamıştır (Goldman ve Mokuvos, 1991, s.25-28). Bu uygulamalarla ekonomide etkinlik ve verimliliğin artırıldığını gören ülkeler, İngiltere başta olmak üzere, günümüze kadar klasik devletten başkasının yapamayacağ 1 düşünülen ve çoğu imtiyaz teşkil eden alanlarda da özel sektörün etkinliğinden yararlanma yolları aramaya başlamıştır (Tekin, 2004b; Morledge ve diğerleri, 2006, s.196-197; United Nations Research Institute for Social Development [UNRISD], 2006, s.259-269; Hemming, 2006, s.4-10; Livesey, 2008, s.1-4; Holden, 2009, s.313-314).

Kamu-Özel Ortaklığı (KÖO), kamu hizmetlerinin özel sektör katkısı ile gerçekleştirilebildiği geniş bir finansman alanını kapsamaktadır. Bu anlamda, hastaneden otoyola, altyapıdan enerjiye, savunmadan hava alanına, okuldan ceza evine ve sair alanlarda uygulanması mümkün olan her türlü kamusal mal ve hizmeti kapsamına almaktadır (Klijn ve Teisman, 2003, s.137-145; Bettignies ve Ross, 2004; Brown, 2005; Davis, 2005; UNRISD, 2006 s.259-269; National Treasury PPP Unit, 2007, s.5; Bhat, 2009 , s.4). Kısaca KÖO, kamu hizmetlerinin devletçe klasik yollardan temini ile tüm hizmet temininin özel sektör aracıllı̆̆ ile yapılmasının arasındaki yelpazede yer alan, devlet ve özel sektörün birlikte katılımını içeren, her iki tarafın da güçlü yanları ile katkı sağladığı (UN, 1993, s.18), tüm mal ve hizmet temini modellerini içeren bir üst kavramdır (Holden, 2009, s.320).

Tüm dünyada hükümetler diğer altyapı yatırımlarında olduğu gibi sağlık sektöründe de büyük yatırımlar yapma gereği ile karşı karşıyadır. Mevcut birçok hastane ve diğer sağlık tesisleri modern sağlık bakım hizmeti vermek için uygun değildir. Artan finansal ihtiyaçlarla başa çıkabilmek tüm dünya yönetimlerini sağlı sektörü için imtiyaz uygulamaları ile ilgilenmek zorunda bırakmıştır. İmtiyazlar İngiltere yönetim politikasında, Ulusal Sağlık Hizmetleri için sermaye programında merkez rol oynayan bir seçenek olmuştur (Bult-Spiering ve Dewulf, 2006).

KÖO çerçevesinde özel bir firmanın bir kamu hastanesi inşaa etmesi, sahip olması ve işletmesi söz konusu olabileceği gibi, bir kamu hastanesinin özel yönetimi, bir özel firmanın yeni bir kamu hastanesi kurması ve sonra tekrar hükümete kiralaması gibi uygulamalara da yer verilmektedir. Avustralya'da özel firmalar tarafindan işletilen kamu hastanelerinde sermaye maliyetlerinin kamu sektöründeki hastaneler ile kıyaslandığında \%20 daha düştüğü ve hükümet tarafından işletilen hastanelere göre klinik hizmetlerini daha ucuza sunduğu görülmüştür (Dutz, 2003; Nikolic ve Maikisch, 2006; Yescombe, 2007; Rissbacher ve diğerleri, t.y.). 
Brezilya'da hükümet tarafindan kurulan ve finanse edilen 12 yeni hastane özel firmalarla yapılan sözleşmelerle özel firmalara devredilmiştir. Hükümet bu uygulama ile hastanelerin verimliliğini ve kalitesini yükseltmeyi amaçlamıştır. Avrupa ülkelerinden ise kamu-özel ortaklığına örnekler İsveç ve İngiltere'den gelmektedir. İsveç'te bir özel hizmet sunucusuna 240 yataklı bir kamu hastanesi kiraya verilmiş ve işletme maliyetlerinde \%30 tasarruf sağlanmıştır. İngiltere'de son 20 yılda birçok kamu hastanesinin finansmanı, inşaası ve yönetiminde kamu-özel ortaklı̆̆ kullanılmıştır. Bu program altında çamaşırhane, güvenlik, temizlik, park ve yemek gibi tıbbi olmayan hizmetlerin sağlanması için özel firmalarla sözleşmeler yapılmıştır. İngiltere'de hükümet 2007'ye kadar 155 adet hastane projesi için 8.5 milyar pound harcamıştır. Bu projelerin devamı olarak 15.5. milyar pound harcanması planlanan KÖO hastane programı bulunmaktadır. (Barlow, Eylül 2007; Shaoul ve diğerleri, 2008).

KÖO hasta bakım kalitesinin iyileştirilmesi ve maliyetlerin kontrol edilmesi için güçlü bir araç olmasına karşın, hükümetlerin sağlık hizmetlerine ulaşım, finansman, dikey ve yatay hastane birleşmeleri ile hastaneler arasındaki rekabet olgusuna dikkat etmesi gerekmektedir. KÖO kamu hastanelerinin klinik olmayan hizmetleri, klinik destek hizmetleri, özel klinik hizmetleri dışarıdan (özel firmalardan) satın alması şeklinde olabilir. Ayrıca KÖO kamu hastanesinin özel yönetimi; yeni bir kamu hastanesinin özel firma tarafından finansmanı, inşaa edilmesi ve tekrar kamuya kiralanması; kamu hastanesinin özel firmaya satımı (özel firma, tesisi yine hastane olarak işletmelidir) ve alternatif kullanım için kamu hastanesinin özel firmaya satımı (satış sözleşmesi gereği tesisi firma hastane olarak işletmeyebilir, örneğin, otele dönüştürebilir) şeklinde uygulamalara yer verilebilmektedir (BultSpiering ve Dewulf, 2006, s.1-2; Roth, 1987, s.123-145; Yescombe, 2007, s.43). Londra'da West Middlesex Hastanesi vakası kamu sektörü için ödenen paranın karşılığının alındığı imtiyaz projelerine iyi bir örnektir (Bult-Spiering ve Dewulf, 2006).

\section{Dünyada Kamu-Özel Ortaklığı Uygulamaları}

KÖO birçok ülkede uzun bir geçmişe sahiptir, fakat daha popüler olması 1980'li y1llarda gerçekleşmiştir. Bu yıllarda özel sektörün kamu sektöründe kullanılması düşüncesi gündeme gelmiş ve kamu mal ve hizmet sunumunda piyasa koşulları uygulanmaya başlamıştır (Morledge ve diğerleri, 2006, s.233-249). 1990'lı y1llara gelindiğinde birçok ülkede piyasa tabanlı felsefe ve yeni kamu yönetimi fikri kamu yönetimini etkisi altına almıştır. Kamu ve özel sektör arasında daha fazla ortaklık oluşması, taraflar ve imzalanan anlaşmalar gereği iç bağımsızlı̆̆ı artması ve daha karmaşık sorunların çözümlenmesi gereği bu durumu ortaya çıkarmıştır (Bult-Spiering ve Dewulf, 2006; Hemming, 2006, s.58).

1990'lı yıllarda İngiltere'de KÖO programının geliştirilmesinin ardından, hem Avrupa'nın diğer yerlerinde hem de dünyanın başka birçok yerinde, giderek artan sayıda ülke KÖO programı başlatmış ve bunun ihraç edilebilir bir kavram olduğunu göstermiştir (IFSL, 2003; Schmidt ve Moisa, 2003; Stone, 2004; Ellis, 2008a; Ellis, 2008b; Holden, 2009).

Dünyada KÖO çok çeşitli sektörlerde uygulama alanı bulmaktadır. İlk projeleri gölge geçiş ücreti esasına dayalı modellerden oluşan ulaştırma sektörü, çoğu zaman önde gelmektedir. Uygulamalarda ulaştırma sektöründeki KÖO'ları demiryolu ve şehir ulaşımını da içermektedir. KÖO'larda önemli payı olan diğer sektörler ise eğitim, savunma, su, sağl1k ve cezaevleri KÖO’larıdır (IFSL, 2003).

KÖO modelleri geliştiren başlıca Avrupa ülkeleri arasında İrlanda, Portekiz, İspanya, İtalya, Almanya, Yunanistan ve Hollanda bulunmaktadır. Orta ve Doğu Avrupa'da Çek Cumhuriyeti, Macaristan, Polonya, Bulgaristan ve Litvanya dâhil birçok ülke, çok önemli altyapı ihtiyacıyla beraber ciddi bütçe kısıtlamaları nedeniyle KÖO’larını başlatmıştır (IFSL, 2003).

Avrupa dışında, en büyük ilgi ise Avustralya, Japonya, Kanada ve Güney Afrika'dan (Canadian Union of Public Employees (CUPE), 8 Mart 2006; National Treasury PPP Unit, 2007; South African Public Private Partnerships, t.y.) gelmiştir. Bu ülkelere yukarıda sayılanlar dışında KÖO'nı sınırlı şekilde uygulamaya başlayan Kuzey ve Güney Amerika, Arjantin, Brezilya, Şili, Meksika, Uzak Doğu ve 
Pasifik'te ise Yeni Zelanda, Güney Kore, Hong Kong ve Singapur'u eklemek doğru olacaktır. Hong Kong ve Singapur'da KÖO'lar özelleştirme programı ile birlikte geliştirilmektedir. 2000 yılından bu yana, birçok ülke KÖO programlarını geliştirmek üzere merkezi yönetim birimleri kurmuştur (IFSL, 2003).

ABD KÖO'nın en uzun geçmişe sahip olduğu ülkedir. ABD'de KÖO 1950 ve 1960'larda bölgesel ekonomik kalkınma ve şehir içi altyapı yatırımlarına özel sektörü çekmek için bir araç olarak kullanılmıştır (Stephenson, 1991, s.109; Linder, 1999, s.35-51; Moulton ve Anheier, 2001). 1980'ler boyunca KÖO giderek özelleştirmeye kayan bir hal almıştır. Bu kapsamda özel tedarikçilerin mal ve hizmetleri daha düşük maliyet ve daha yüksek kalitede sunabileceği varsayımı ile kamunun iş ve sorumlulukları giderek azaltılmıştır (UN, 1993, s.27; Linder, 1999, s. 35-51; Bult-Spiering ve Dewulf, 2006; Hemming, 2006, s.9).

Avrupa'nın diğer ülkeleri de 1980'lerin sonlarında KÖO'nı kullanmaya başlamıştır. Örneğin, Hollanda'da KÖO fikri 1986 hükümet politika açıklamasında açıkça yer almıştır. Zengin bir ülke olan Norveç’te son yıllarda özellikle birçok altyapı çalışmalarında KÖO uygulanmaktadır (Bult-Spiering ve Dewulf, 2006).

Avrupa ve Amerika dışında KÖO uygulama örnekleri de mevcuttur. Örneğin Avustralya'da 1990'ların başında altyapıların yenilenmesi konusunda kamu-özel işbirlikleri kullanılmıştır. 1990'ların ortalarında ilk projeler otoyol, hastane, su ve enerji alanında gerçekleşmiştir. 1990'ların sonlarında havaalanları, stadyumlar, limanlar bu yöntemle yapılmıştır. 2001'de ise bu listeye savunma, okullar ve mahkemeler de eklenmiştir. Avustralya örneği maliyet etkili, erken proje teslimi, yenilikten (Barlow, 2008, s. 1401) elde edilen başarı, bazı proje ve finansman riskinin özel sektöre devri ve vatandaşa sunulan hizmetin ulaşılabilir ve kaliteli olması gibi olumlu sonuçlar ortaya çıkarmıştır (English, 2007a, 313-336).

Belçika, Fransa, Almanya, Yunanistan, İrlanda, Portekiz ve İspanya kapsamlı KÖO yasalarına sahiptir. Merkezi hükümet düzeyinde KÖO birimleri kurulmuştur. Bu birimlerin amaçlarından birisi KÖO'nı organize etmektir. Üye ülkeler KÖO'nı taşımacılık, halk sağlığı, eğitim ve ulusal güvenlik gibi altyap1 projelerinin gerçekleştirilmesi için gerekli bir yapı olarak görmektedir (Bult-Spiering ve Dewulf, 2006). Avrupa Topluluğu mevzuatı KÖO için özel kurallar içermemektedir. Fakat üçüncü şahıslarla yapılan sözleşmeler 1957 Roma Anlaşmasında belirtilen prensip ve kurallara tabidir. $\mathrm{Bu}$ kurallar: eşit muamele, şeffaflık, ölçülülük, karşılıklı tanınma prensiplerinden oluşmaktadır. Ayrıca $\mathrm{AB}$, üye ülkelerin $\mathrm{KÖO}$ uygulamalarında sorunların çözümü için yeni direktifler içeren bir "Yeşil Rapor" yayınlamıştır (Bult-Spiering ve Dewulf, 2006). Yeşil Rapor Avrupa düzeyinde geçerli yasal bir çerçevenin oluşturulması, tamamlanması ya da açık hale getirilmesi ile ilgilenmektedir.

Avrupa'da bazı ülkeler KÖO uygulamalarında ileri düzeyde gelişme gösterirken bazıları orta düzeyde bazıları ise henüz başlangıç düzeyinde gelişme göstermektedir. Ayrıca bazı sektörler diğer sektörlere göre KÖO uygulamaları için daha uygundur. Örneğin ulaşım sektöründeki KÖO'larında ödenen paranın karşılığı sağlanırken uygulama örnekleri yeni başlayan sağlık ve eğitim gibi sektörlerde henüz başarı sağlandığını gösterememiştir (Renda ve Schrefler, 2006, s. 1). KÖO'nın genişlemesinde politik beklentilerin etkisini de küçümsememek gerekir. Sağlık, eğitim ve hapishane hizmetleri gibi geleneksel olarak kamu sektörünün ana faaliyet alanındaki sektörler için bazı yenilikçi KÖO modelleri geliştirmelerine rağmen bazı AB üyesi ülkelerde bu alanlarda KÖO kullanımı hala tabudur (Renda ve Schrefler, 2006, s.2; McKee ve diğerleri, 2006, 890-896; Bult-Spiering ve Dewulf, 2006, s.126).

KÖO ugulamaları açısından bakıldığında $\mathrm{AB}$ üyesi ülkeler 3 grupta incelenebilir: İngiltere, bazı açılardan Fransa, Almanya, İrlanda ve İtalya gibi "KÖO'na ileri düzeyde uyum sağlamış" ülkeler; İspanya ve Portekiz gibi henüz tüm sektörlerde olmasa da KÖO'nda kapsamlı bir başarı göstermiş olan "orta düzeyde uyum göstermiş ülkeler ve Lüksemburg ve İsveç gibi KÖO uygulamalarında henüz başlangıç düzeyinde olan "geç takip eden (latecomers)" ülkeler olarak sınıflandırılabilmektedir (Torres 
ve Pina, 2001, s.610-613; Renda ve Schrefler, 2006, s.2; Bult-Spiering ve Dewulf, 2006, s. 119; Barlow, 2008, s.1392-1401).

KÖO uygulamalarında bazı AB ülkeleri özellikle dikkat çekmektedir. Bunlardan birisi Yunanistan'dır (Korres, 2008). Yunanistan'da Atina Uluslararası Havalimanı, yollar, spor ve sosyal tesisler gibi projelerde ileri düzeyde KÖO uygulamalarından yararlanırken diğer sektörlerde uygulanmamaktadır (Besley ve Ghatak, 1999; Renda ve Schrefler, 2006, s.3; Bult-Spiering ve Dewulf, 2006, s.59, 74). Merkez ve Doğu Avrupa ülkeleri ise eski üye ülkelerin deneyimi ile karşılaştırıldığında KÖO sözleşmeleri için yeterli uzman ve uzmanlık kapasitesine sahip olmadığı için önemli zorluklar yaşayan ülkelerdir. Bu ülkelerde KÖO'nın en yaygın başarısızlık sebebi, Polonya ve Macaristan örneklerinde görüldüğü gibi, hizmetler için potansiyel talebin yanlış tahminlenmesi, başlangıçta özel sektöre devredilen talep riskinin sonradan kamu tarafından üstlenilmek zorunda kalmasıdır. Bunların yanında Çek Cumhuriyeti hükümet bütçesinden ayrı bir kaynak aktarmak zorunda kalmadan başarıyla altyapı hizmetlerinin nasıl yapılabileceğine ilginç bir örnektir (Renda ve Schrefler, 2006, s.3).

Yukarıda değinildiği gibi KÖO deneyimleri sektörel ve ülkeden ülkeye farklılık göstermektedir. Bu bölümde KÖO uygulamalarına ülkeler bazında biraz daha yakından bakalım.

\section{İngiltere}

Dünyada KÖO uygulamalarını kurumsallaştıran ilk ülke İngiltere'dir. İngiltere'de eğitimden sağlığa, hapishanelerden çöp atık sistemine kadar pek çok alanda, 900'den fazla projenin gerçekleştirilmesi için KÖO yöntemleri kullanılmıştır. İngiltere KÖO yönteminin diğer ülkelerde de kurumsallaşması için çalışmalar yürütmektedir (Schneider, 1999; Stone, 2004; Holden, 2009).

KÖO kavramı, İngiltere'de kamu varlıklarının finansmanı için özel sermaye kullanımını daha önce ciddi biçimde kısıtlayan kuralların 1989 yılında yürürlükten kaldırılmasından sonra, 1992 yılında gerçekleşmiştir. Amaç, KÖO’nı sağlık ve yerel yönetim gibi sektörlerde yaygınlaştırmaktır. Ancak bu 1990’lı yılların ortalarında eşgüdüm eksikliği ve çok az zamanda çok fazla sayıda projenin ele alındığı doğrudan ve yetersiz özelleştirme ve projelerde mali olarak karara varılmasını zorlaştıran bir dizi engel bulunması yüzünden engellenmiştir (IFSL, 2003; Flinders, 2005, s.220).

Özel Finansman Girişimi (Private Finance Initiative-PFI) İngiltere'de hükümetin en yaygın kullandığı KÖO modelidir. Bu model hükümetin daha önceki girişimleri sonucu gelişmiş; özelleştirme ve eksiltme ile başlayan sürecin üçüncü aşaması olmuştur (IFSL, 2003). 1990'l1 yılların başlarından bu yana toplam olarak 24 milyar pound tutarında KÖO projesi imzalanmıştır. Bu tutarın 17 milyar pound kadarı, yani üçte ikisinden fazlası, 1997 yılında KÖO tipi projelere ilişkin engellerin kaldırılmasının ardından gerçekleşmiştir. Ulaştırma Bakanlığı tarafından yaptırılan projeler, imzalanan anlaşmaların üçte birinden fazlasını oluşturmuş, ayrıca sağlık, savunma ve eğitim bakanlıklarının önemli payları olmuştur (IFSL, 2003; Flinders, 2005, s.221). İngiltere bu tarihten itibaren 2004 yılının sonuna kadar 677 KÖO projesiyle KÖO'nda çok uzun yol kat etmiştir. KÖO özellikle 2000'den sonra hız kazanmış ve toplam kamu yatırımlarının \%11'ini oluşturmuştur. HM Treasure'un 2003 yılındaki son raporuna göre, KÖO'nın kilit sektörü (34'ten fazla hastane ve 119 sağlık planı ile) sağlıktır. Sağlığı 239 yeni okul binası ve onarımıyla eğitim, bölgesel idari yatırımlar (itfaiye ve polis istasyonları), atık ve su projeleri ile ulaşım ve savunma takip etmektedir. Projelerin parasal değerleri göz önüne alındığında ise resim değişmektedir. 2004 y1lı sonuna kadar imzalanan KÖO projelerinin yaklaşık \%51'i demiryolu sektörüne (Londra'da 3 yeraltı treni projesi, Channel Tunnel Demiryolu bağlantısı) aitken, \%11'i sağllk projelerine, \%7'si eğitim ve \%3'ü hapishane projelerine aittir. Karayolu ve köprü projeleri toplam KÖO projelerinin \% 9'unu oluştururken, hava trafik kontrolü ve su tedarik projeleri \%13'ü oluşturmaktadır (Flinders, 2005, s.220; Renda ve Schrefler, 2006, s.1-11).

İngiltere'de KÖO ile ilgili merkezi düzeyde tüm sektörlere ve yerel yönetimlere yardım sağlayan bir ünite oluşturulmuştur (Flinders, 2005, s.220). "Hazine Görev Gücü" adı verilen bu birimin kurulması, 
başlıca ticari sorunlara eşgüdümlü ve standart bir yaklaşım getirmiştir. Özellikle KÖO tipi projelerde kullanılmak üzere bir rehber yayınlanması, verimliliğin artmasına yardımcı olmuştur. Hazine Görev Gücü'nün işi daha sonra iki organizasyon tarafından geliştirilmiştir. Bunlar: Partnerships UK ve Devlet Ticaret Bürosudur.

Partnerships UK: İngiltere'de KÖO'ların oluşturulmasında çok önemli bir rol oynamakta ve bunların denizaşırı ülkelerde geliştirilmesine destek olmaktadır. Hazine Görev Gücü gibi Partnerships UK de özel sektörün uzmanlığı ile güçlü bir kamu sektörü misyonunu birleştirmiş ve kendisini de bir KÖO haline getirmiştir.

Devlet Ticaret Bürosu: Kamu sektöründe ticari faaliyetlerin tedariki ve sunumu sirasında ödenen paranın karşılığının sağlanması amacıyla katalizör olarak merkezi ve yerel yönetimlerle birlikte çalışır. $\mathrm{Bu}$, tedarik, proje, program, risk ve hizmet yönetimindeki en iyi uygulamalarla ilgili bir rehber hazırlamayı ve dağıtmayı sağlamaktadır. Bu rehber, geleneksel tedarik ve KÖO'lar dâhil, tüm tedarik biçimlerini kapsamaktadır.

İngiltere'de KÖO’nı geliştirmek amacıyla birçok çalışma yürütülmüştür. Bunlar:

Projeye odaklanma: Sağlık ve yerel yönetim dâhil olmak üzere birçok sektör için öncelik sırasının belirlenmesi, kamu sektörü ve özel sektör kaynaklarının nispeten daha az sayıda ve yerine getirilme şansı makul bir düzeyde bulunan öncelikli projelere odaklanmasına olanak sağlamıştır.

Teknik engellerin ortadan kaldırılması: Hükümet, KÖO’ların varolan yasal çerçeveye uygunluğu konusunda özel sektörün endişelerini gidermek amacıyla bazı alanlarda yeni yasalar çıkarmıştır.

Esnek KÖO yaklaşımı: Tasarla, yap, finanse et ve işlet modeline (TYFİ) dayanan tipik KÖO, birçok tesisin teslimine uygun hale getirilmiştir. Bununla beraber, özellikle yeni yatırım gerektirebilecek durumlarda, istenen hizmetlerdeki değişikliklere esneklikle karşılık verebilmek için özel sektörün sözleşme yapısı içinde sınırlı olanağı bulunmaktadır. Bu değişiklikler, kamu sektörü tarafından daha önce kolaylıkla tahmin edilemeyen politika farklılıkları veya teknolojik gelişmeler nedeniyle ortaya çıkabilir. Bu nedenle, KÖO'nın diğer modelleri geliştirilmiştir. Bunlardan bazıları tasarla, yap, finanse et, devret (TYFD), yap, işlet, devret (YID), yap, işlet, sahip ol (YIS) ve TYFI'dir. Ancak esnekliğin artırılması, her bir KÖO’nın her projenin koşullarını karşılayacak şekilde biçimlendirebilmesi anlamina gelmektedir.

Uygulama deneyimleri ve kurumsallaşmış bir KÖO yapısı İngiltere'de özellikle danışmanlık sektörünü geliştirmiştir (Spackman, 2002). Bu danışmanlık firmaları sahip oldukları bilgi birikimlerini (know how) diğer ülkelere pazarlamaktadır (Stone, 2004; Holden, 2009). Bu ülkelerden birisi de Türkiye'dir. Özellikle henüz kurumsallaşamamış ülkelere yabancı yatırımcıyı çekebilmek için bu firmalar aracılık etmektedir (Tekin ve Çelik, 2010).

\section{Amerika Birleșik Devletleri}

Amerika Birleşik Devletleri genellikle diğer ülkelerle kıyaslandığında kamu altyapı tedarikinde özel sektörün görece çok geniş rol oynadığı bir ülkedir. ABD'de KÖO'nın en yaygın uygulandığı sektör su ve atık sudur. Belediyelerin yaklaşık \%15'i bu yolla projelerini gerçekleştirmektedir. 1980'lerden beri özel hapishane sektörü önemli bir gelişme göstermiştir. Bu alanda genellikle franchise yöntemi kullanılmaktadir (Yescombe, 2007, s.39-41).

Amerika'da son zamanlarda ulaştırma sektörü için büyük ölçüde KÖO'larından yararlanılmaktadır. 19. yy boyunca karayolları büyük ölçüde özel sektör finansmanı ile gerçekleştirilmiştir. 20. yy'ın ilk yarısında kamu fonu ile otoyol ve köprü inşaatları gerçekleşmiştir. 1950'lerin sonlarına doğru gerçekleştirilen yeraltı treni projelerinin finansman kaynakları yakıt ve araçlardan alınan vergilerle sağlanmıştır. Ancak artan yatırım miktarı, yönetimleri yeni finansman kaynağı bulmaya itmiştir. $\mathrm{Bu}$ amaçla 1990'ların başında özellikle Virginia ve California'da metro yapımında çeşitli yöntemlerle özel sektörün katılımı sağlanmıştır (Bult-Spiering ve Dewulf, 2006; Yescombe, 2007, s.39-41). 


\section{İspanya}

İspanya'da otoyol imtiyazları özel sektör tarafından geliştirilen otoyol, köprü ve demiryolu projelerinin gerçekleştirildiği 19. yy'da başlamıştır (Torres ve Pina, 2001, s.610; Yescombe, 2007, s.46-47; Allard ve Trabant, 2007, s.1). İspanya KÖO uygulamaları için ulusal bir uzmanlık merkezine sahip değildir. Ancak bu ülkede KÖO ile tedarik süreci daha hızlı ve daha düşük maliyetlidir. Bunun en temel nedeni KÖO ihalelerine başlamadan önce tasarım, planlama, çevresel etki değerlendirmesi ve danışmanlardan yararlanma konusunda kamu düzeyinde uzman bir yapıya sahip olunmasıdır (Yescombe, 2007, s.46; Allard ve Trabant, 2007, s.1).

İspanya'da özel sektör otoyol geliştirme programı 1967'de başlamış, 1976'ya kadar 1500 km'yi kapsayan 15 imtiyaz anlaşması imzalanmıştır. 1998-2003 yılları arasında toplam değeri 6 milyar Euro'yu bulan 22 karayolu imtiyaz anlaşması imzalanmıştır. 1972'de yürürlüğe giren imtiyaz yasası başlangıçta sadece karayolu sektörü için düşünülmüşse de 2003'de KÖO modellerini kapsayan yeni bir yasal düzenleme yapılmıştır. Son yıllarda İspanya altyapı yatırımlarının yaklaşık \%20'si KÖO ile gerçekleştirilmektedir (Yescombe, 2007; Torres ve Pina, 2001, s.610; Menendez, Aralık 2002; Allard ve Trabant, 2007, s.1).

İspanya'da KÖO uygulamaları bölgesel ve merkezi yönetim olarak farklı düzeylerde uygulama alanı bulmaktadır. Yerel yönetimler kendi ihtiyaçlarına uygun projelerde KÖO uygulamalarından yararlanırken, merkezi yönetim bölgelerini aşan projelerde devreye girerek kendisi KÖO uygulamalarını kullanabilmektedir. İspanya'da 70 ve 80 'lerde benzer kamu-özel işbirlikleri ile karayolu yapımları gerçekleştirilmesine rağmen ilk KÖO uygulamaları 1990'larda başlamıştır.

İspanya KÖO uygulamalarında sağlık sektöründe de hızlı bir ilerleme göstermektedir. The Madrid Nuevas Infraestructuras Sanitarias 2007 Madrit'te 9 hastane projesi geliştirmiştir. Şimdiye kadar 2004'de yalnızca 1 hastane projesi başlamıştır. Bu proje 30 yıllık yap, işlet, bakımını yap şeklinde oluşturulmuş bir imtiyazdır. Bu deneyim başarıyla gerçekleşirse diğer projelerde uygulamaya geçecektir (Torres ve Pina, 2001, s.611; Renda ve Schrefler, 2006, s.7).

Başarıyla uygulanan KÖO uygulamaları yanında bazı sektörlerde KÖO’ları gerçekleştirilememiştir. Örneğin "Ulusal Su Yönetimi" projesi çevrecilerin muhalefeti nedeniyle hayata geçirilememiştir. İspanya'da KÖO uygulamalarında karşılaşılan en önemli engeller projelerin finansmanı ile ilgilidir. Uluslararası sermaye piyasalarının ulaşımı bölgesel oyuncuların baskınlığından dolayı sınırlıdır. Var olan yasal çerçeve proje uygulaması sırasında ortaya çıkabilecek problemler açısından finansman tarafının hakları ile ilgili olarak eksiklikler içermektedir (Torres ve Pina, 2001, s.611; Renda ve Schrefler, 2006, s.7). Son y1llarda İspanya KÖO'nı tüm sektörlerde ve tüm düzeylerde uygulayıp uygulamamak konusunda ciddi bir kamu yönetim sıkıntısıyla karşı karşıyadır (Allard ve Trabant, 2007, s.11).

\section{Avustralya}

Amerika gibi federal bir ülke olan Avustralya'da KÖO uygulamaları eyaletler düzeyinde gerçekleşmektedir. Bu KÖO uygulamalarının çoğu iki eyalette gerçekleşmiştir. Bunlar; New South Wales ve Victoria eyaletleridir. Hacimsel olarak bakıldığında en büyük paya otoyol projeleri sahip olmasına rağmen, özellikle Victoria eyaletinde sosyal altyap1 projelerinde de KÖO'nın geliştiği söylenebilmektedir (Yescombe, 2007, s.41; English, 2007a, s.313-336; Hodge, 2007).

Victoria Department of Treasury and Finance 2000 yılında bölüm içinde bir uzmanlık birimi olarak "Partnerships Victoria" birimini kurmuştur. Sosyal KÖO projeleri bu birim altında KÖO yöntemi ile 2002 yılında Victoria Eyalet Mahkemesi Projesi ile çalışmalarına başlamıştır. Bu birimin kurulmasına kadar diğer eyaletlerle hemen hemen aynı durumda olan Victoria Eyaleti bundan sonra KÖO’ları için 
yaygın kullanım alanı olan rehber dokümanlar oluşturmuş ve diğer eyaletler bu dokümanları bir standart olarak kendilerine uyarlamışlardır (Yescombe, 2007, s.41).

Avustralya Federal Hükümeti'nin KÖO'ları ile ilgili olarak dış ilişkileri kapsayan küçük bir koordinasyon birimi vardır. Bundan dolayı Victoria Eyaleti merkez hükümet ve tüm eyaletlerden üyelerin olduğu, kamu sektöründe bilgi ve deneyimlerin paylaşılması, yargılamalara karşı tutarlı bir yaklaşım geliştirmek ve ihale maliyetlerini azaltmak için 2004'de Ulusal KÖO Forumu'nu başlatmıştır (Yescombe, 2007, s.41; IFSL, 2003).

KÖO'nın Avustralya'da popüler olmasının birçok nedeni vardır. Bunlar: nüfusuna oranla kıtasal büyüklüğü, vatandaşların kamu hizmetleri ile ilgili beklentileri, yeni kamu yönetimi reform gündeminin uygulanması yönünde idarenin ideolojik yaklaşımları, vatandaşların daha fazla vergi yükü istememeleri, kamu borçlarını kontrol altına almak ve azaltma ihtiyacıdır.

1997-2004 döneminde Victoria Eyaleti’nde kamu hastane bakım hizmeti sunmak için altı KÖO uygulaması gerçekleşmiştir. İlk uygulamalar Latrobe Bölge Hastanesi (1997) ve Mildure Base Hospital (1999)'dır. Bu projeler KÖO'nın yap, sahip ol, işlet modeli ile gerçekleşmiştir. Bu iki KÖO projesi 1 Eylül 1998 'de zamanında ve mali programa uygun şekilde tamamlandıktan 2 yıl sonra başarısız olmuştur. 2002'de idare kamu ve özelden gelen yoğun eleştirilerden dolayı hastanenin tüm varlığını ve yönetimini geri almıştır. Hastanenin başarısızlığı, anlaşmanın hem kamu hem de özel taraflarının süreçte ve beklentilerdeki zayıflıkları olduğunu göstermiştir (Yescombe, 2007, s.41; English, 2007a, s.313-336). Bundan sonra KÖO modeli değişmiştir. 2002'de Casey (daha önceki ismi ile Berwick) Hastanesi ve 2004 yılında Royal Womens Hospital anlaşmaları imzalanmıştır. Bu projeler ise KÖO'nın yap, sahip ol, işlet, devret modeli ile gerçekleştirilmiştir. Bu iki projenin ilk iki projeden iki önemli farkı vardır. İlki sözleşmeler projenin sonunda varlığın idareye devrine ilişkin bir madde içermektedir. İkincisi ise kamu hastane hizmetleri sunumu hariç tutulmaktadır. Klinik hizmetler ilgili bölge sağlık otoriteleri tarafından sağlanmaktadır. Diğer iki sözleşme (St. Vincent's Hospital ve The Austen and Mercy Hospital) ise 2004'de imzalanmıştır. Bu anlaşmalarda yeni fon düzenlemeleri, ortaya çıkan tesisin sağlamlaştırılması, yeniden tefriş edilmesi ve geliştirilmesini de içerdiği için maddesel olarak farklılık göstermektedir (Yescombe, 2007, s.41; English, 2007a, s.313336; Hodge, 2007).

\section{Güney Afrika}

Güney Afrika, ekonomik büyüme açısından karmaşık bir yatırım ve finans sektörüne sahip, gelişmekte olan bir ülke olmasına rağmen, KÖO konusunda önemli başarılar elde etmiş bir ülkedir. 1990'ların ortalarında otoyol projelerinde imtiyaz yönteminin kullanılması ile KÖO uygulamalarına başlayan ülke, ilk olarak 1996 yılında Mozambik'deki Maputo Limanı ile Güney Afrika'yı birleştiren N4 otoyol projesini gerçekleştirmiştir. Daha sonraki aşamada 11 tane hapishane projesinin çalışmaları başlamış, ancak maliyet hesaplamalarındaki hatalarından dolayı sadece 2 hapishane için sözleşme yapabilmiştir (Yescombe, 2007, s.47; National Treasury PPP Unit, 2007). 2007'ye kadar Güney Afrika'da 20 KÖO projesi aktif şekilde uygulanabilmiştir (National Treasury PPP Unit, 2007; South African Public Private Partnerships, t.y.).

Güney Afrika'nın en kapsamlı projesi 2001 yılında Hazine kontolünde gerçekleştirilen Inkosi Albert Luthuli Hospital projesidir. Bu hastane dünyada kâğıtsız işleyen birkaç hastaneden biridir. Hastanenin bilgi teknolojileri ve tıbbi ekipmanlarının güncellenmesinden ve tesis yönetiminden özel sektör sorumludur (National Treasury PPP Unit, 2007, s.24.).

Güney Afrika KÖO’yu bir süre yakından inceledikten sonra, 1997 yılında hükümete bağlı bir KÖO Özel Görev Gücü, 2000 yılında da bir KÖO birimi oluşturmuştur. Bu birim fizibilite hazırlık aşaması sonras1, tedarik dokümantasyonu öncesi ve final dokümantasyonunun imzalanmasından önce sürece katılmaktadır. Ayrıca, 2000 yılında çıkarılan Kamu Finansman Yönetimi Yasası KÖO’ların 
uygulanmasını düzenlemektedir (IFSL, 2003; Yescombe, 2007,s.47; South African Public Private Partnerships, t.y.). KÖO birimi tarafindan, ağırlıklı olarak İngiltere'deki formlara dayanarak oluşturulan, standart KÖO sözleşme formları özel sektör yatırımcı ve finansörlerinin görüşleri alındıktan sonra 2004 yılında yayınlanmıştır (Yescombe, 2007, s.47).

\section{Portekiz}

Portekiz'in KÖO deneyimi iddialı ve öğretici bir süreç olarak tanımlanabilir. 1995'ten beri çeşitli kamu sektörlerinde uygulama deneyimi olan Portekiz KÖO uygulamalarında önemli bir mesafe kaydetmiştir (Monteiro, 2005; Renda ve Schrefler, 2006, s.5-6). Yaklaşık on beş y1l önce ortaya çıkan KÖO ile kamu ve özel sektör arasında 30 yıllık sözleşmelerle bir kamu tesisinin tasarım, yapım, işletim, bakım ve onarımı ya da zaten var olan bir kamu tesisinin kullanımı özel sektöre verilmiştir.

Başlangıçta ulaştırma sektörüyle başlayan KÖO uygulamaları sağlık sektörü, su, atık tesisleri, öğrenci yurtları ve hapishanelerle ilgili projelerde de kullanılmaktadır. Portekiz diğer AB ülkeleri ile kıyaslandığında bütün KÖO yatırımları ve sektörlere göre yatırım miktarları açısından önemli bir noktadadır (Monteiro, 2005). Portekiz ulaştırma sektöründen sonra sağlık sektöründe de KÖO programları geliştirmiştir. 10 hastanenin KÖO ile yapılması ile ilgili çalışmalar yürüten Portekiz'de sadece büyük hastane projeleri değil rehabilitasyon merkezleri ve çağrı merkezleri gibi daha küçük projeler için de KÖO kullanılmaktadır. Portekiz'de hastane KÖO uygulamalarında İngiltere örneğinde olduğu gibi yalnızca hastane yönetimi değil klinik hizmetler de özel sektöre devredilmektedir (Monteiro, 2005).

KÖO’ları finansmanının özel sektör veya kamu tarafından karşılandığı Portekiz KÖO altyapı yatırımlarını hızlandırmak ve hizmet kalitesini artırmak açısından etkili olmuştur, ancak ekonomik açıdan kamuya yeni sıkıntılar getirmiştir. Başlangıçta bütçede kısa dönemli bir rahatlama getirse de bazı uzun dönemli projelerin bütçe üzerinde önemli etkileri olmuştur. Kamu yıllık bütçeleme içinde bu uzun dönemli KÖO projelerinin maliyetlerini yeterli şekilde ele alamamıştır. Bu açıdan Portekiz'de son zamanlarda KÖO'larının uzun dönemli bütçeye etkisi, sözleşme yapıları gibi konularda kurumsal çerçevede değişiklikler yapılmaktadır (Monteiro, 2005).

Portekiz'de KÖO ile ilgili yapılan yapısal değişikliklerin başında kamu özel ilişkilerini araştırmak, veri toplamak, değerlendirmek ve tüm sektörlerde KÖO projelerinde yardımcı olmak sorumluluğuna sahip, hatta projelerin pek çok aşamasında sürece dâhil olan bir KÖO biriminin oluşturulmasıdır. Adı "Parpublica" olan birim birçok büyük ölçekli ulaşım ve hastane projesinde yer almıştır (Monteiro, 2005). Portekiz'de mali yasalar KÖO ile ilgili prosedürü açıkça tanımlamaktadır. Bunlardan bazıları projeler için hangi KÖO modelinin seçileceğine finans bakanlığı uzmanlarının katkısı ile ve kamu sektör karşılaştırması yapılarak karar verilebileceği şeklindedir (Monteiro, 2005; Renda ve Schrefler, 2006, s.5-6).

Portekiz su ve atık yönetimi, okul, hapishane, yüksek hızlı trenler ve yeni bir uluslararası hava alanını içeren 20 milyar Euro'luk yatırım projeleri için çalışmalarını sürdürmektedir (Renda ve Schrefler, 2006, s.5-6). Sonuç olarak Portekiz'de KÖO uygulamaları kamu sektör tedariki ile karşılaştırıldığında özellikle altyapı yatırımlarında kamu hizmetleri için olumlu bir alternatif olmuştur. Ancak bu olumlu sonuç ekonomik değil daha çok etkililik analizinin sonucudur (Monteiro, 2005; Renda ve Schrefler, 2006, s.5-6). Bu nedenle dikkat edilmesi gereken şey kapsamın doğru belirlenmesi, ilerideki maliyetin doğru tahmin edilmesi, gelir akışının doğru yapılması açısından gerektiğinde projelerin yeniden gözden geçirilmesi önemlidir. Sonuç olarak KÖO Portekiz'de özel sektörün artan uzmanlığına karşı kamunun insan kaynağı gücü yetersiz kalacaktır. Ancak orta vadede KÖO için özel olarak oluşturulan Parpublica SA, taraflar arasındaki bilginin toplanması, analiz edilmesi ve yayılmasını sağlayarak bu gibi sorunları ortadan kaldırmayı planlamaktadır (Renda ve Schrefler, 2006, s.5-6). 


\section{Fransa}

Fransa'nın kamu altyapı yatıımlarında imtiyaz yöntemini kullanması 17. yy'ın ortalarında Atlantik'den Akdeniz'e uzanan "Canal du Midi" ile başlayan uzun bir geçmişe sahiptir. 19.yy boyunca ve 20. yy'ın ilk yarısında imtiyazlar genel çerçevede atık yönetimi ve şehir taşımacılığı gibi hizmet alanlarında yaygın şekilde kullanılmıştır. Enerji ve demiryolu gibi hizmet alanları da benzer şekilde imtiyazlar çerçevesinde sağlanmıştır (Yescombe, 2007, s.43).

İmtiyazlar dışında Fransa'da kullanılan KÖO türlerinden bir diğeri ise "Affermage" (Franchise)'dir. $\mathrm{Bu}$ yöntemde kamu tarafından altyapı yatırımı yapılan bir tesis talep riskinin özel sektöre devrini öngören bir sözleşme ile işletim hakkının özel sektöre devredilmesidir. Fransa'da Affermage sözleşmelerinin en yaygın kullanıldığı sektör su sektörüdür (Hall, 1998; Chong ve diğerleri, 2006, s.149-169).

Fransa sağlık ve hapishane projelerini kapsayan sosyal altyapı yatırımlarında KÖO kullanımına sektöre özel yasalar oluşturarak 2002 yılında başlamıştır. Fransa'nın 1.3 milyar Euro hapishane ve 1.4 milyar Euro hastane KÖO programları halen devam etmektedir. Genel KÖO yasasını 2004'de çıkaran Fransa karayolu sektöründe yeni imtiyaz projeleri, ücretli otoyol işletimi sektöründe ise franchise uygulamalarına devam etmektedir (Yescombe, 2007, s.43).

\section{Türkiye}

Türkiye'de KÖO modelleri özellikle 90'lı yıllarda gündeme gelmiş, elektrik üretimi, içme suyu vb alanlarda yap, işlet, devret ve yap, işlet türü uygulanmıştır (Gümüşstekin, 1992). Ancak siyasi, ekonomik ve hukuksal altyapı ile siyasi istikrarsızlık ve sözleşme tasarımında yapılan hatalar, kamu ve özel sektör işbirliği açısından ciddi olumsuzluklar getirmiş, kamuoyu önünde bu modellerin güvenirliliği tartışılır hale gelmiştir. Avrupa Birliği'nin, birlik üyesi ülkelerin altyapı hizmetlerinin, KÖO modeli olarak anılan model ile sağlanması konusundaki somut düzenlemeleri ve bu konuda ayırdığı fonlar ile ülkemizde özellikle 2003 yılı içerisinde özel sektörün bu konudaki girişimleri devletçe bu konuda somut adımların atılmasını gündeme getirmiştir (Gümüştekin, 1992; Tekin, 2004a; Tekin, 2004b; Tekin, 2007).

Ülkemizde, KÖO’nın ilk yasal zemini Osmanlı döneminde yürürlüğe giren, 10 Haziran 1326 tarihli (23 Haziran 1910) "Menafii Umumiyeye Müteallik İmtiyazat Hakkında Kanun”u oluşturmaktadır. Bu kanun Cumhuriyetin kurulmasından sonra da imtiyaz oluşturan hizmetlerin özel sektöre devrinin genel yasal dayanaklardan biri olmaya devam etmiştir (Gümüştekin, 1992; Şeker, 1994, s.4; Çiçek, 2002; Yavaş, 2003; Tekin, 2004a; Tekin, 2004b; Eren, 2006; Eker, 2007; Yüzer, 2007; Tekin, 2007). Cumhuriyet dönemindeki gelişmeler ise 1980'li yıllara uzanmaktadır. 1984 tarihli, 3096 sayılı Kanun ve ardından çıkarılan 4283 sayılı Yİ Modeli Hakkında Kanun ile o dönemde öncelikli görülen elektrik üretimi alanında, YİD; İşletme Hakkı Devri ve Yİ yöntemleri uygulamaya konulmuştur (Gümüştekin, 1992). Bu yöntemler ile ülkemizin kurulu elektrik santrali gücünün (35 bin MW) yaklaşık dörtte biri tutarındaki 30 adet enerji santrali (8500 MW) işletmeye alınmıştır (Yüzer, 2007). Bunların kurulu güç açısından yaklaşık \%90'ını teşkil eden 16 adet enerji santrali, Hazine Müsteşarlığı tarafından sağlanan Hazine garantileri yoluyla gerçekleştirilmiştir. Bunlara ilave olarak, 1988 yılında çıkarılan 3465 sayılı kanunla da Karayolları Genel Müdürlügü̈'nün uhdesinde bulunan otoyol yapım ve bakım hizmetlerinin özel sektörce yapılabilmesi imkânı getirilmiştir.

1994 yılında çıkarılan 3996 sayılı Kanunla YİD modeli "ileri teknoloji ve yüksek maddi kaynak ihtiyacı duyulan projelerin gerçekleşmesinde kullanılmak üzere geliştirilen özel bir finansman modeli" olarak tanımlanmıştır. Bu kanunun uygulama alanının genel olarak imtiyaz sözleşmelerini içermesi nedeniyle uygulamada çıkan bazı anayasal sorunlara rağmen, bu kapsamda özellikle elektrik üretimi alanında projeler hayata geçirilmiştir. 
1997 yılında çıkarılan 4823 sayılı Kanun ile elektrik üretim tesislerinin Yİ Modeli ile kurulabilmesi sağlanarak Yİ modeli de KÖO uygulamaları arasına alınmıştır. 2006 yılında çıkarılan 5539 sayılı Kanunla bu kanunda yapılan değişiklikle bu kanun kapsamında Türkiye Elektrik İletim Anonim Şirketi (TEİAŞ) ile yapılacak anlaşmaların özel hukuk sözleşmeleri olması hükme bağlanmıştır (Tekin, 2007; Gülen, t.y.).

1999 yılında Anayasada yapılan değişikliklerle YİD sözleşmelerinin özel hukuk hükümlerine ve uluslararası tahkime tabi olma imkânı getirilerek uygulamada karşılaşılan temel sorunlar giderilmiştir. 2004 yılında 5183 sayılı Kanunla Danıştay Kanununda yapılan değişiklikle YİD ve Yİ konularında ihtisas dairesi oluşturularak yargısal alanda etkinlik artırılmıştır (Gülen, t.y.).

90'l1 yıllara gelindiğinde Devlet Hava Meydanları İşletmesi Genel Müdürlüğü’nün yürüttüğü KÖO uygulamaları gündeme gelmiştir. Devlet Hava Meydanları İşletmesi tarafından, İstanbul, Antalya 1 ve 2, Dalaman, Ankara ve İzmir Havalimanları, Hazine garantisi olmaksızın YİD yöntemi ile hayata geçirilmiştir. Benzer biçimde, Karayolları Genel Müdürlüğü Göcek Tüneli Projesini YIDD modeli ile yürütmektedir (Tekin, 2004a; Tekin, 2004b; Tekin, 2007). Uygulamada ciddi başarılar elde eden DHMİ Genel Müdürlüğü 6 projeyi tamamladıktan sonra yeni bir açılım başlatmış YID dönemi sona eren, terminallerin özelleştirme yöntemi ile uzun vadeli işletme haklarını devredip kiralayarak özel sektöre tekrar devretme çalışmalarını yürütmüştür. Bu çalışmaların özü özel sektör tarafından yapılan, bunun karşıllğında işletilen ve işletme dönemleri sona eren terminallerin yeniden devletleştirmeye gidilmeden tekrar özel sektöre devrini sağlamaktır (Tekin, 2010).

KÖO ile ilgili Yİ modelinin geliştirilmesi, YİD modelinde karşılaşılan problemlerin çözümlenebilmesi için bir çerçeve oluşturulması amaciyla 1998'de Hazine Müsteşarlığı ve Özelleştirme İdaresi'nin de katkı verdiği bir ön çalışma başlatılmıştır. Bu kapsamda Dünya Bankası'ndan alınan bir hibe ile çalışmanın danışmanlık ihalesi yapılmıştır. Ancak hükümet değişikliği gibi siyasi nedenlerle bu çalışma o dönemde sonuçlandırılamamıştır. 2006-2007 yıllarına gelindiğinde yine Dünya Bankası hibesi ile Hazine Müsteşarlığı ECORYC adlı firma ile aynı çalışmayı yeniden başlatmak üzere anlaşmış ve iki etaplı bir projenin çalışmaları başlatılmıştır. Çalışma 2. nesil KÖO'larının yapısal düzenlemeleri ile ilgili iki aşamadan oluşmaktadır. Birinci aşamada KÖO'nın çerçevesinin çizilmesi ve yeniden yapılandırılması, ikinci aşamasında ise KÖO kanununun hazırlanması ve bu yapının uygulamaya geçirilmesi planlanmıştır. İlk aşamayı tamamlayan ECORYC hazırladığı raporda eğitim, standart kontratlar, merkezi birimin ve danışma kurullarının oluşturulması gerekliliği gibi bütün ana unsurlara vurgu yapmıştır. Projenin ikinci aşaması gerçekleştirilememiştir. Ancak birinci aşama sonucunda çıkan bilgiler ışığında kanun çalışmaları başlatılmış ve AKP hükümet programlarında KÖO kanununun hazırlanması görevi Devlet Planlama Teşkilatı (DPT)'na verilmiştir. Bu görev nedeniyle DPT birçok kurumun görüş ve önerilerini alarak birkaç kez KÖO Çerçeve Kanun taslak çalışması yapmıştır. Ancak taslak kanun çalışmaları bir türlü yasalaşamamıştır (Tekin, 2010).

2003-2004 yıllarında demiryollarında KÖO ile ilgili çalışmalar başlatılmıştır. Ancak demiryolları KÖO ile ilgili mevzuat yetersizliği, tepe yönetimin kararlı olmayışı, kurum içi bilgilendirilme ve ikna sürecinin tam olarak gerçekleştirilememesi, sivil toplum örgütleri ve kuruluş arasında ortak bir mutabakat sağlanamaması nedeniyle devam edememiştir (Tekin, 2010).

2005 yılında çıkarılan 5302 sayılı İl Özel İdaresi Kanunu, 5355 sayılı Mahalli İdare Birlikleri Kanunu ve nihayet 5393 sayılı Belediye Kanunu ile yerel yönetimlerin görev alanlarına giren yatırımlarda YİD veya Yİ modeli ile çalışmalarına imkân sağlanmıştır (Eren, 2006).

Sağlık sektöründe KÖO uygulamaları hizmet alımı şeklinde başlamıştır. 4.Ocak.1985 tarihinde Sağlık Bakanlığı'nın devlet hastanelerinin temizlik hizmetlerini dışarıdan (özel firmalardan) satın alması için yayınladığı genelge ile başlayan (Tatar, 1993, s.286) KÖO, temizlik hizmetleri dışında, mutfak, güvenlik, bilgisayar bakım-onarım vb. birçok tıbbi olmayan destek hizmetlerin özel firmalardan sağlanması ile devam etmiştir (Gider ve Top, 2007). İmtiyaz şeklindeki KÖO yöntemleri ise sağlıkta 
kur, işlet, devret (KIDD) modeli olarak uygulanmıştır. Kamu hastane sektöründe KIDD modeli özellikle bilgisayarlı tomografi ünitesi, MR ünitesi gibi ileri düzey teşhis ve ayakta bakım birimleri için geçerlidir. Modele göre bilgisayarlı tomografi veya MR cihazı olan özel müteşebbis, cihazını bir kamu hastanesine kurarak belirli bir süre kendi adına çalıştırmaktadır. Sözleşmede belirlenen süre sonunda cihaz hastaneye devredilmektedir (Tatar, 1993, s.293-294).

Sağlık sektöründe ilk somut KÖO düzenlemesi 2005 yılında 5396 sayılı Kanunla Sağlık Hizmetleri Temel Kanunu'na eklenen bir madde ile yapılmıştır (Tekin ve Çelik, Nisan 2010, Tengilimoğlu ve diğerleri, 2010). Buna göre (Sağlık Hizmetleri Temel Kanununa Bir Ek Madde Eklenmesi Hakkında Kanun, 2005): Yüksek Planlama Kurulu (YPK)'nca karar verilmesi halinde Hazine (veya gerekiyorsa şahıs) arazileri üzerine özel sektörce yapılacak sağlık tesisleri Bakanlıkça belirli bir süre üst hakk1 verilmek suretiyle kiralanacak, tıbbi hizmetler dışındaki tüm hizmetler özel sektör tarafından verilebilecektir. Yap-Kirala-Devret olarak adlandırılabilecek bu KÖO modeli ile ilgili uygulama yönetmeliği Temmuz 2006'da yürürlüğe girmiştir (Sağlık Hizmetlerinin, Kiralama Karşıllı̆ı Yaptırılması İle Tesislerdeki Tıbbi Hizmet Alanları Dışındaki Hizmet ve Alanların İşletilmesi Karşılığında Yenilenmesine Dair Yönetmelik, 2006). Yönetmelikle beraber KÖO hastane projelerinin hazırlık çalışmaları başlamışırır (Tekin ve Çelik, Nisan 2010).

Özellikle İngiltere'de uygulanan KÖO modeline benzeyen bu yöntemle özellikle büyük sağllk tesislerinin yapılması planlanmaktadır. "Şehir Hastaneleri”" olarak adlandırılan bu tesisler içinde farklı alanlarda uzmanlaşmış ihtisas hastanelerinin, yüksek teknolojiye sahip laboratuvarlar, araştırma merkezleri ve sağlık teknoparklarının, sosyal tesislerin, otel ve medikal otellerin, alışveriş merkezi, idari merkezler, merkezi acil ve yoğun bakım ünitelerinin, merkezi eczane ve depo yapılarının, konaklama imkânları, atık yönetimi, yeterli büyüklükte otopark peyzaj alanları ve üstün nitelikteki teknolojik, fiziksel altyapı koşulları ile bir bütün olarak tasarlanan sağlık kompleksleri olup; sağlık hizmetlerinin son basamağı ve sağlı tesislerinin en uzmanlaşmış hali olarak tanımlanmaktadır. Şehir Hastaneleri için Yozgat, Manisa, Adana, Kayseri, Ankara (Etlik ve Bilkent) ve İstanbul (İkitelli) gibi pilot bölgeler seçilmiştir. Bu pilot bölgeler dışında farklı büyüklükteki 120 sağlık kompleksinin KÖO yöntemi ile yapılması hedeflenmektedir (Tekin, 2010).

\section{Sonuç}

1990'lı yıllarda İngiltere'de KÖO programının geliştirilmesinin ardından, hem Avrupa'nın diğer yerlerinde hem de dünyanın başka birçok yerinde, giderek artan sayıda ülke KÖO programı başlatmış ve bunun ihraç edilebilir bir kavram olduğunu göstermiștir. KÖO, kamu hizmetlerinin özel sektör katkısı ile gerçekleştirilebildiği geniş bir finansman alanını kapsamaktadır. Bu anlamda, hastaneden otoyola, altyapidan enerjiye, savunmadan hava alanına, okuldan ceza evine ve sair alanlarda uygulanması mümkün olan her türlü kamusal mal ve hizmeti kapsamına almaktadır.

Birçok sektörde olduğu gibi neo-liberalizmin küreselleşmesi sağlık sektörüne devletin müdahalesini azaltmış ve artık hükümetler sağlık sektöründeki birincil ve asli sorumluluklarını azaltma davranışları sergilemeye başlamışlardır. Bu süreç kamu hastaneciliği alanına da yansımıştır. Bu kapsamda birçok ülkede hastane reformlarında öncelikle kamu hastanelerinin merkezi hükümetin birer bütçe birimi olmaktan çıkıp, kendi gelir ve giderlerinden sorumlu daha otonom, özerk veya özelleştirilmiş hastane özelliğine kavuşturulması amaçlanmaktadır. Ancak daha önce kamu hastanelerinin yenilenmesi ve günün ihtiyaçlarını karşılayabilen modern tesislere dönüştürülmesi gerekmektedir. Bu kapsamda KÖO yöntemi birçok yönetim için finansman ihtiyacını karşılayabilecek önemli bir finansman alternatifi olabilmektedir. Öyle görülmektedir ki bu alternatif finansman yöntemi önümüzdeki yıllarda popülerliğini sürdürecek bir yönetim aracı olmaya devam edecektir. 


\section{Kaynaklar}

ALLARD, G. VE TRABANT, A. (2007). Public-private partnerships in Spain: lessons and opportunities. IE Business School Working Paper, WP10-07.

BARLOW, J. (Eylül 2007). Redefining healthcare infrastructure: integrating services and the built environment. Revaluing Construction 2007-Crossing Boundaries, Health and Care Infrastructure Research and Innovation Centre-HaCIRIC, Copenhagen.

BARLOW, J. VE KÖBERLE-GAISER, M. (2008) The private finance initiative, project form and design innovation the UK's hospitals programme. Research Policy, 37, 1392-1402.

BESLEY, T. VE GHATAK, M. (1999). Public-private partnerships for the provision of public goods: theory and an application to NGOs. The Development Economics Discussion Paper Series, 17.

BETTIGNIES, J-E. VE ROSS, T. W. (2004). The economics of public-private partnerships. Canadian Public Policy, 30, 2.

BHAT, R. (1999). Public- private partnerships in health sector: issues and prospects. IIMA Working Papers, Indian Institute of Management Ahmedabad, Research and Publication Department, Erişim:12.5.2008, http://econpapers.repec.org

BROADBENT, J. VE LAUGHLIN, R. (Şubat 2005). The role of PFI in the UK governments modernisation agenda. Financial Accountability and Management, 21, 1.

BROADBENT, J. VE RICHARD, L. (2003). Public private partnerships: an introduction. Accounting, Auditing and Accountability Journal, 16, 3, 332-341.

BROWN, C. (2005). Policy forum: financing public infrastructure financing transport infrastructure: for whom the road tolls. The Australian Economic Review, 38, 4, 431-439.

BULT-SPIERING, M. VE DEWULF, G. (2006). Strategic Issues in Public-Private Partnerships in International Perspective. Blackwell Publishing, Oxford, UK.

Canadian Union of Public Employees (CUPE). (8 Mart 2006). Britain having second thoughts about PFI hospitals. Erişim: 5.Aralık.2008, http://cupe.ca

CHONG, E., HUET, F., SAUSSIER, S. VE STEINER F. (2006). Public-private partnerships and prices: evidence from water distribution in France. Review of Industrial Organization, 29, 149169.

ÇIÇEK, A.K. (2002). Finansman Modeli Olarak Yap-Işslet-Devret Modeli ve Atatürk Hava Limanı Yeni Dış Hatlar Terminal Binası ve Katlı Otoparkı Projesinde Uygulanması. Yüksek Lisans Tezi, Anadolu Üniversitesi, Sosyal Bilimler Enstitüsü, İşletme Anabilim Dalı, Eskişehir.

DAVIS, K. (2005). Policy forum: finansing public infrastructure PPPs and infrastructure investment. The Australian Economic Review, 38, 4, 439-44.

DUTZ, M. (2003). PPP Systems for good governance of public service provision: A menu of support options for contract design, bidding and monitoring. Draft Discussion Document, The World Bank Group. Erişim:12.5.2010, http://info.worldbank.org/etools/docs/library/86466/ses2.1_pppsystemsgoodgov.pdf

EKER, A.Y. (2007). Kamu Özel Sektör Ortaklıkları. Bütçe Dünyası, 2, 25.

ELLIS, O. (2008a). Difference between quantitative and qualitative VfM criteria. Partnerships UK.Erişim:21.02.2009, www.partnershipsuk.org.uk 
ELLIS, O. (2008b). VfM in PPP projects: introduction to the concept. Partnerships UK. Erişim:21.02.2009, www.partnershipsuk.org.uk

ENGLISH, L.M. (2007). Performance audit of Australian public private partnerships: legitimising government policies or providing independent oversight? Financial Accountability and Management, 23,3, 0267-4424, 313-336

EREN. F. (2006). Kentsel Dönüşümlerde Kamu-Özel Ortaklıkları ve Özel Girişimin Dönüşümdeki Varlığı: Konya Örneği. Yüksek Lisans Tezi, Selçuk Üniversitesi, Fen Bilimleri Enstitüsü, Şehir ve Bölge Planlama Anabilim Dalı, Konya.

FLINDERS, M. (2005). The politics of public-private partnerships. BJPIR, 7, 215-239.

Gider, Ö. ve Top, M. (2007). Kamu Hastane Sektöründe Liberalleşme ve Türkiye'de Yansımaları. Erişim: 27.05.2008, http://www.ekonomist.net/ kamu-hastane-sektorunde-liberallesme-veturkiyede-yansimalari/

GOLDMAN, H. VE MOKUVOS, S. (1991). Dividing the Pie Between public and Private. R.L. Kemp (Ed.). Privatization: The Provision of Public Services by the Private Sector. McFarland and Company, Inc., Publishers, USA.

GÜLEN F. (t.y.). Özelleştirme, Yap-İşlet-Devret, Kamu Özel Sektör İşbirliği. İnceleme, Yerel Yönetimler Araştırma Yardım ve Eğitim Derneği (YAYED). Erişim: 25.6.2009, http://www.yayed.org.tr/genel/bizden_detay.php?kod=719\&tipi...

GÜMÜŞTEKIN, A. (1992). Build-Operate-Transfer Model For Investment Projects: A Comparison with Social Benefit-Cost Analysis. Yüksek Lisans Tezi, Ortadoğu Teknik Üniversitesi, Fen Bilimleri Enstitüsü, Endüstri Mühendisliği Anabilim Dalı, Ankara.

HALL, P. A. (1998). Governing The Economy: The Politics of State Intervention in Britain and France. Oxford University Press, New York.

HEMMING, R. (2006). Public-Private Partnerships, Government Guarantees, and Fiscal Risk. International Monetary Fund, Washington D.C.

HODGE, G. (2007). Public-private partnerships: The Australiasian experience with physical infrastructureç. G. Hodge ve C. Greve (Ed.). The challenge of public-private partnerships: learning from international experience. Edward Elgar Publishing.

HOLDEN, C. (2009). Exporting public-private partnerships in healthcare: export strategy and policy transfer. Policy Studies, 30, 3, 313-332.

International Financial Services London (IFSL). (2003). Kamu-Özel Sektör Ortaklıkları: Uluslararası Pazarlar için İngiltere Uzmanlığı. Trade Partners UK, KPMG, Norton Rose, PriceWaterhouseCoopers, Partnerships UK.

KLIJN, E.H. VE TEISMAN, G.R. (2003). Institutional and strategic barriers to public-private partnership: an analysis of dutch cases. Public Money and Management.

KORRES, L. (2008). Novelty and opportunities in the Grek PPP market. Special Secretary for Public Private Partnerships Ministry of Economy and Finance, Greece.

LINDER, S.H. (1999). Coming to terms with the public-private partnership, a grammar of multiple meanings. American Behavioral Scientist, 43, 35-51.

LIVESEY, P. (2008). PPP and PFI. HM Treasury. 
MCKEE, M., EDWARDS, N. VE ATUN, R. (2006). Public-private partnerships for hospitals. Bulletin of The World Health Organization, 84, 890-896.

MENENDEZ, L.S. (Aralık 2002). Public-Private Partnerships and Innovation Policy: The Spanish Experience [Bildiri]. Joint Mexico-OECD Conference on International Public/Private Partnerships for Innovation, Puerto Vallarta, Mexico.

MONTEIRO, R.S. (2005). Public private partnerships: some lessons from Portugal. EIB Papers, 10, 2, 72, European Investment Bank, Luxemburg.

MORLEDGE, R., SMITH, A. VE KASHIWAGI, D.T. (2006). Building Procurement, Blackwell Science, Oxford, UK.

MOULTON, L. VE ANHEIER, H. K. (2001). Public-private partnerships in the United States: historical patterns and current trends. Civil Society Working Paper, 16, 14.

National Treasury PPP Unit. (2007). Introducing Public Private Partnerships in South Africa, National Treasury PPP Unit.

NIKOLIC, I. A. VE MAIKISCH, H. (2006). Public-Private Partnerships and Collaboration in the Health Sector: An Overview with Case Studies from Recent European Experience. HNP Discussion $\quad 37807 . \quad$ Paper, 3 Erişim:14.4.2010, http://info.worldbank.org/etools/docs/library/240103/PUBLIC $\sim 2 . P D F$

RENDA, A. VE SCHREFLER, L. (2006). Public Private Partnerships National Experiences In The European Union. European Parliament DG International Policies of The Union, Directorate A, Economic and Scientific Policy, Briefing note No. IP/A/IMCO/SC/2005-160.

RISSBACHER, C., GÜNTERT, J.B. VE MAIKISCY, H. ( t.y.). Public Private Partnership in The Austrian Healthcare System. UMIT.

Sağlık Hizmetlerinin, Kiralama Karşılığı Yaptırılması İle Tesislerdeki Tıbbi Hizmet Alanları Dışındaki Hizmet ve Alanların İşletilmesi Karşılığında Yenilenmesine Dair Yönetmelik, 2006

SCHMIDT, R.H. VE MOISA N. (2003). Public private partnerships (PPP) in financial development in South-East Europe. Erişim:7.05.2007, http://economix.uparis10.fr/pdf/sem_economix/2006-03-16_schmidtmoise

SCHNEIDER, A.L. (1999). Public-pirvate partnerships in the U.S. prison system. American Behavioral Scientist, 43,1, 192-208.

SHAOUL, J., STAFFORD, A. VE STAPLETON, P. (2008). The cost of using private finance to build, finance and operate hospitals. Public Money ve Management, April, 101-108.

South African Public Private Partnerships. (t.y.). Erişim:5.12.2008, http://www.ppp.gov.za

SPACKMAN, M. (2002). Public-private partnerships: lessons from the British approach. Economic Systems, 26, 283-301.

STEPHENSON, M.O. (1991). Whither the public-private partnership: a critical Overview. Urban Affairs Quarterly, 1,27, 109-136.

STONE, D. (2004). Transfer agents and global networks in the "transnationalization" of policy. Journal of European Public Policy, 11, 3, 545-566.

ŞEKER, S. (1994). Serbest Bölgelerde Yap İşlet Devret Modeli Uygulaması ve İmtiyazlı Şirketler. Yaklaşım, 4. 
TATAR, F. (1993), Privatization and Turkish Health Policy. Yayınlanmamış Doktora Tezi, University of Nottingham, Nottingham.

TEKIN, A.G. (2004a). Özelleştirmede Yeni Yaklaşım: Özel Sektör Kamu İşbirlikleri (Public Private Partnerships veya PPP Modelleri). Ekonomistler Bülteni, Mayıs.

TEKIN, A.G. (2004b). Özelleştirmede İkinci Dalga: Kamu-Özel Sektör İşbirlikleri (PPP Modeli). Ekonomistler Bülteni, Haziran.

TEKIN, A.G. (2007). Kamu-Özel Sektör İşbirlikleri- Kamu-Özel Ortaklıkları/Public Private Partnerships veya PPP Modelleri. İdarecinin Sesi Dergisi, 21, 122.

TEKIN, P.Ş. VE ÇELIKK, Y. (Nisan 2010). Analysing public-private partnership policy as a financing method in Turkey health sector with political mapping. [Bildiri], 7th Biennial Conference in Organisational Behaviour in Health Care, Mind the Gap: Policy and Practice in the Reform of Health Care, University of Birmingham, Birmingham, UK.

TENGILIMOĞLU, D., ÇELIK, Ö.F. VE TEKIN, P.Ş. (2010). Kamu Özel Ortaklığı. M. Bulun (Ed.). Sağlık Hizmetlerinde Güncel Kavramlar. Sage Yayınları, 21, Ankara.

TORRES, L. VE PINA, V. (2001). Pubic-private partnership and private finance initiatives in the EU and spanish local governments. The European Accounting Review, 10, 3, 601-619.

UN. (1993). Public/Private Partnerships in Enabling Shelter Strategies. United Nations Centre for Human Settlements (Habitat), Nairobi.

United Nations Research Institute for Social Development-UNRISD, (2006). Public Sector Reform In Developing Countries: Capacity Challenges To Improve Services. Y. Bangura ve G.A. Larbi (Ed.)., Palgrave Mac Millian, Newyork.

YAVAŞ, A. M. (2003). Yap İşlet Devret Modeli Çerçevesinde Kamu Hizmeti İmtiyaz Sözleşmeleri ve Tahkim. Yüksek Lisans Tezi, Kocaeli Üniversitesi, Sosyal Bilimler Enstitüsü, Kamu Hukuku Anabilim Dal, Kocaeli.

YESCOMBE, E.R. (2007). Public-Private Partnerships: Principles of Policy and Finance, Elsevier, UK.

YÜZER, M. (2007). Enerji Sektöründe Yap İşlet Devret Modelinin Diğer Finans Modelleri ile Karşılaştırılması. Yüksek Lisans Tezi, Gazi Üniversitesi, Sosyal Bilimler Enstitüsü, İşletme ABD, Muhasebe-Finansman BD, Ankara. 